\title{
Home adaptations for persons with chronic disabilities: an educational model.
}

Ruth E. Levine

Thomas Jefferson University

Laura N. Giltin

Thomas Jefferson University

Follow this and additional works at: https://jdc.jefferson.edu/otfp

Part of the Occupational Therapy Commons

Let us know how access to this document benefits you

\section{Recommended Citation}

Levine, Ruth E. and Giltin, Laura N., "Home adaptations for persons with chronic disabilities: an educational model." (1990). Department of Occupational Therapy Faculty Papers. Paper 57. https://jdc.jefferson.edu/otfp/57

This Article is brought to you for free and open access by the Jefferson Digital Commons. The Jefferson Digital Commons is a service of Thomas Jefferson University's Center for Teaching and Learning (CTL). The Commons is a showcase for Jefferson books and journals, peer-reviewed scholarly publications, unique historical collections from the University archives, and teaching tools. The Jefferson Digital Commons allows researchers and interested readers anywhere in the world to learn about and keep up to date with Jefferson scholarship. This article has been accepted for inclusion in Department of Occupational Therapy Faculty Papers by an authorized administrator of the Jefferson Digital Commons. For more information, please contact: JeffersonDigitalCommons@jefferson.edu. 


\title{
Home Adaptations for Persons With Chronic Disabilities: An Educational Model
}

\author{
Ruth E. Levine, Laura N. Gitlin
}

\author{
Key Words: community health services • \\ education, occupational therapy • \\ environment, physical
}

This paper offers a method by which to train students in the provision of culturally relevant, in bome environmental adaptations for persons with chronic disabilities. On the basis of a theoretical framework, the student therapist learns about the client's life-style and offers adaptations that evolve from a collaborative problem-solving process. The training process bas been developed and refined over a 3-year period. A case study illustrates the student's application of theory and practice and the outcome for the client of this service provision approach.

Ruth E, Levine, EdD, OTR/I, FAOTA, is Professor and Chair, Department of Occupational Therapy, College of Allied Health Sciences, Thomas Jefferson University, 130 South 9th Street, Philadelphia, Pennsylvania 19107.

Laura N. Gitlin, PhD, is Assistant Professor, Department of Occupational Therapy, College of Allied Health Sciences, Thomas Jefferson University, Philadelphia, Pennsylvania.

This article was accepted for publication April 3, 1990.

$\mathrm{O}$ ccupational therapists have traditionally prescribed environmental adaptations to pro mote independence in clients with disabilities. Adaptations are tools that simplify an aspect of the environment and extend the client's ability to perform desired tasks in self-care, work, and leisure. Therapists, however, have not been conventionally trained to evaluate the environment and a client's culture, interests, goals, and roles in order to promote an optimal fit between the selected adaptation and the client's needs. The emphasis instead has been on the client's dysfunction and the assignment of equipment or other adaptations to promote independent functional ability.

This paper describes an educational program for senior undergraduate- and graduate-level occupational therapy students. This approach (a) teaches the student how to evaluate the client's life-style; (b) teaches the student to assess competence with the use of environmental cues; (c) orients the student to Barris's (1982) model of the environment to provide a framework from which to evaluate client-environment fit (Barris, Kielhofner, Levine, \& Neville, 1985); and (d) offers in-home adaptations for persons with chronic disabilities, which evolve from a collaborative, problem-solving process. A case example demonstrates the effectiveness of this approach in the training of students about the importance of assessing a client's cultural values when choosing and implementing a strategy and when following up on treatment.

\section{Background}

Due to diagnosis-related groups, rising costs, shrinking resources, and increasing numbers of noninstitutionalized persons with chronic disabilities, the home is emerging as an important practice site for the provision of services. Federal and state agencies have targeted the development of coordinated commu nity-based services as a priority (Philadelphia Corporation for Aging, 1989). Such community-based services as home care focus on the client's needs and have the potential to ameliorate some of the negative conditions that prevent persons with chronic disabilities from functioning independently in their own homes and neighborhoods. Nevertheless, the medically stable but chronically disabled population continues to be underserved in the health care marketplace. Few funding sources exist for the increasing number of clients who are unable to make what Medicare guidelines define as "reasonable progress" (U.S. Department of Health and Human Services, 1982, p. 15.1), but who, due to illness or trauma, require services to facilitate adaptation to daily living and new roles. Examples of such persons include the elderly. 
diabetic person who received rehabilitation after a leg amputation but who may still need assistance to resume desired life roles and daily tasks and the person who is schizophrenic and lives alone but is unable to organize living space and time to carry out daily activities. More important than the concept of cure in these cases is the need to promote adaptation to improve the quality of the clients' lives.

Occupational therapy services offer one means of ameliorating selected environmental factors that create stress and infringe on daily functioning for the chronically ill population. Environmental adaptations can improve the fit between the person and the external stimulation from the environment. The adjustment of the level of environmental stimulation to maximize a client's feelings of competency and mastery necessitates a treatment model that incorporates the concepts of life-style (i.e., how a person leads his or her life) and environment (Barris, 1982; Kielhofner, 1985; Kielhofner \& Burke, 1980, 1985; Kielhofner, Burke, \& Igi, 1980; Reilly, 1974; Rogers, 1983). The therapist must think of the client as an open system involved in a dynamic, interactive relationship with the human and nonhuman environ. ment. The individual influences the environment and, in turn, the environment influences the individual, to create the "just right challenge" (Burke, 1977, p. 255) for the client.

Students often have difficulty understanding the life-styles of clients who are chronically dysfunctional. Traditional didactic training approaches and clinical fieldwork placements usually do not provide opportunities for in-depth exploration of client-environment transactions. Consequently, for the last 3 years, the Department of Occupational Therapy at Thomas Jefferson University in Philadelphia, Pennsylvania, has been using a program in which students are teamed with persons with chronic disabilities for one semester under the supervision of a faculty mentor and an agency-based supervisor. The students each receive a client referral, use an evaluation tool, observe the client's life-style, learn about the client's values and culture, identify environmental constraints, and develop adaptations to promote the client's feelings of independence and competence. The service provision model focuses on how the therapist can learn about the client's culture and use this information to adjust or grade selected factors in the environment to enhance the client's performance.

\section{Concepts Used in Training}

The selection and implementation of an adaptation to enhance client-environment compatibility is rooted in the understanding of both the environment and the client's values, interests, and life-style.

\section{Environment}

Historically, occupational therapists have conceived of the environment in their practice rather broadly as the composite of all external forces and influences that affect the development and maintenance of an individual (Dunning, 1972; Dunton, 1918; Tracey, 1912). Therapists have long felt that the environment could promote or retard treatment progress (Allen, 1985; Kannegieter, 1980; Mosey, 1968; Parent, 1978). Over the past 20 years, various conceptualizations of the environment have evolved in different disciplines by which to examine individual behavior (Institute of Medicine and National Research Council, 1988; Lawton, 1983; Maguire, 1987).

Barris's (1982) model of the environment provides occupational therapists with a framework by which to examine the interactive patterns between the client's behavior and environmental features and understand how choice of and performance in a setting promote the development of individual competence. In this model, the environment is conceived of as four hierarchically organized, concentric layersobjects, tasks, social groups, and culture-that influence physical and social interactions and shape the quality of performance (Barris, 1982; Barris et al., 1985; Elliott \& Barris, 1987). Objects are defined as tangible, stable, visible things used by the client; tasks are defined as a set of activities that share some common purpose recognized by the task performer (Barris et al., 1985; Dunning, 1972; Levine \& Brayley, in press); social groups and organizations are defined as the individuals who form collective opportunities for interaction; and culture is defined as the way in which a group shares a collective way of living and carrying out activities (Barris et al., 1985; Hall, 1969, 1977). Cubie (1985) stated that this four-part conceptualization of the environment is so integral to the treatment process that the consideration and analysis of objects, tasks, social groups, and culture should precede the introduction of activity and other treatments.

\section{Arousal and Press}

Arousal and press are two key processes of client-environment interactions that help the therapist design activities that both satisfy and challenge the client and that also reinforce functional abilities (Barris, 1982; Barris et al,, 1985; Dunning, 1972; Dunton, 1928; Lawton \& Nahemow, 1973; Reilly, 1974; Tracey, 1912). Arousal refers to an internal state in which persons experience both physical and emotional stimulation. Individuals are constantly seeking a personally satisfying match between environmental stimulation and their own needs. Too little arousal may result in boredom, whereas too much arousal may 
result in anxiety. The occupational therapy process involves the selection of activities and tasks that evoke curiosity and interest within the client's comfort zone.

Environmental press, another concept central to the implementation of activity-based treatment, refers to "forces in the environment that together with an individual need evoke a response" (Lawton \& Nahemow, 1973, p. 659; Murray, 1938). Press is neutral, but its stress-producing capacity lies in the person's ability to interact within the environment.

The manipulation of arousal and press in the environment influences the client to engage in meaningful activities between therapeutic visits

\section{Grading}

The match between a client's abilities and an activity involves manipulation of the activity so that it is "appropriately paced and modified to demand the individual's maximum capacities" (Pedretti, 1981, p. 103). Grading is essential in the creation of a successful experience for the client (Cynkin, 1979; Mosey, 1973). Activities must be designed to promote optimal function without anxiety. The activity, however, must be interesting enough to prevent boredom.

\section{Competence}

Competence, broadly defined by Lawton and Nahemow (1973, p. 659) as "a diverse collection of abilities residing within the individual," may be influenced by environmental factors and may change across settings. Adjustments in the arousal and press of the environment can promote or increase individual performance.

\section{Adaptive Equipment}

Adaptive equipment refers to tools designed to reduce the press of environmental demands. These tools serve as extensions of the person's body that compensate for a loss of function or movement. Adaptations range from simple grips and extension bars to complex computerized interventions. Therapists frequently focus on nonhuman adaptations, but other means to reduce environmental demands include human and social adaptations (Rogers, 1982b). For example, a client who needs assistance with putting on his or her shoes may prefer the help of a grand. child over the use of adaptive equipment.

\section{Methodology}

Students in their senior year at Thomas Jefferson University are required to take a three-credit course on the theoretical perspective and concepts introduced above. Additionally, weekly 2-hr laboratories introduce students to a wide range of adaptive techniques and provide hands-on experience in the construction and modification of adaptive equipment. In the beginning of the semester, each student is paired randomly with a person with a chronic disability who has been referred by a participating agency. The student visits the client 6 to 10 times over the course of the semester. Visits average $1 \mathrm{hr}$ or more and require concentration, listening skills, and sensitive interaction. Throughout the semester, students meet with faculty to review field notes and the clinical process. At the end of the semester, each student delivers a 20-min presentation to a panel of faculty and consumers in which he or she identifies the clinical reasoning process, the adaptations developed for the client, and the way in which the approach reflects the client's values, interests, roles, habits, and performance needs.

On the basis of Barris et al.'s (1985) environmental layers, the students analyze the objects, tasks, social groups and organizations, and culture of the client to understand the arousal and press features of the environment and how it impinges on performance. The application of theory to practice is guided by an eight-part approach: (a) introduction and building rapport; (b) evaluation of the client's functional status, life-style, and home environment; (c) introduction of an activity; (d) mutual exploration and identification of problems; (e) mutual exploration of solutions; ( $f$ ) design and construction of adaptions; (g) client instruction in the use of equipment; and (h) disengagement and follow-up.

\section{Introduction, Building Rapport, and Evaluation}

Initial observation and interview is based on a participant-observation approach to data collection. The students become participant observers in the client's world and observe functional performance, social interactions and networks, and environmental considerations. Observation of the human and nonhuman aspects of the environment are important considerations. The students record observations and impressions on structured field-note forms. During this initial phase, the students must develop an empathetic relationship with the client (and caregiver, when appropriate) and bridge the gap between his or her own life-style and values and those of the client (Langness \& Frank, 1986; Spradley \& McCurdy, 1980). The process of careful note taking and postvisit analysis encourages students to examine the life-style of another person reflectively, to identify shared values and in. terests, and to refine the clinical reasoning process by which to frame clinical problems (Rogers, 1983; Schon, 1983).

Introduction of activity. After the initial interaction, the student selects an activity to observe the 
client's performance and to increase rapport. Typical selections have included a game (e.g., bingo, checkers) or an activity of daily living (e.g., meal preparation). Activities may include activities of daily living adaptations, leisure or work, and social interaction or mobility activities, but must reflect the client's interest and choice. This joint-activity venture promotes and improves rapport. During this phase, the student actively engages the client in the interaction and problem-solving process and demonstrates his or her ability to appreciate the client's values.

Introduction of adaptations and client instruction. The student and client begin a collaborative process in which activities and adaptations are developed to reflect the interests of the client and improve the client-environment fit. The student must actively engage the client in the interaction and problem-solving process. Students report having difficulty with this aspect of service provision because problem areas must truly reflect the client's interests and concerns and not necessarily what the student considers to be important.

Disengagement and follow-up. Students express difficulty with closure due to the prolonged engagement in the client's home and the shared interactions that have occurred. Students must learn how to disengage and prepare the client for their departure. Often, students find it helpful to follow up with telephone calls at the end of the semester.

\section{Clients}

The clients are referred by the following Philadelphia agencies: Magee Memorial Hospital, a comprehensive rehabilitation center; Washington Square West, a Section 8 housing center for low-income clients; PATH, a community service agency for adults and children with developmental delays; Resources for Independent Living Center, a community-service agency based on the independent living movement; Philadelphia Geriatric Center, a research and service agency for older adults; Rudolfe House, a residential home for clients with mental retardation; and Our Lady of Hope, a facility for homeless women. Each agency director meets with the program director, signs an affiliation agreement, and agrees to provide a list of eligible clients. An initial pool of approximately 80 clients is needed to ensure 1 client for each of the 40 students in the class. Clients are randomly assigned to the students, who have the opportunity to switch clients among themselves before the interview process. Each student must contact and visit his or her respective client after the agency referral and the client's agreement to participate. The case study described below demonstrates the application of Barris's (1982) model to persons with chronic disabil- ities and the process by which a student enters a client's home and implements the eight-step service provision model.

\section{Case Study}

\section{Student}

Ms. R. is a 21-year-old occupational therapy student in her senior year who has demonstrated good to excellent abilities in both didactic and clinical situations. She is gentle and pleasant and seems interested in and capable of listening patiently to people. Besides her full-time educational responsibilities, she works $15 \mathrm{hr}$ a week at an outside job.

\section{Client}

Mrs. D. is an 84-year-old Caucasian woman who lives in an urban row house in a middle-class neighborhood. She complains of a heart problem and has had 12 heart attacks and a tendon injury to her dominant hand. She was referred by the social worker of a home-visiting program for the elderly. Although once active, Mrs. D. claims that she cannot do anything for herself and is presently confined to her home. She dresses simply and has many somatic complaints.

Mrs. D. has lived in her tidy house for 46 years. Her treasured objects are pictures of cats displayed on the mantle, travel pictures of her and her husband, and jewelry. She also treasured her cat Midgee and, after Midgee's death, her new cat, Samantha.

Mrs. D. interacts with people at the geriatric center, where she sees a social worker and receives Meals On Wheels. Other significant social relations take place with neighbors, the veterinarian, the church deacon, and the grocer and pharmacist, both of whom deliver goods to her home.

Mrs. D. was a housewife who had reportedly "hit bottom" when her husband died. She said that "death was all around her." Her relations with her daughters are distant, and neither came to their father's funeral. Mrs. D. had lavished attention on her cat Midgee, and, after several weeks of grieving Midgee's death, accepted Samantha, the new cat. Mrs. D. takes pride in her house, clothing, and jewelry. She reported that many of her friends were dead.

\section{Procedure}

Significant objects used during intervention were raisin bread, which the student purchased for Mrs. D. for the third visit, a box of muffin mix used in the sixth visit, vegetable soup made by Mrs. D. and reported during the ninth visit, and an address book left by the student during the ninth visit.

The choice of tasks during the nine visits guided the course of intervention (see Table 1). 
Table 1

Summary of Events of Student-Client Visits ${ }^{\boldsymbol{B}}$

\begin{tabular}{|c|c|}
\hline Visit No. & Event \\
\hline 1 & $\begin{array}{l}\text { The student is directed to a chair near the door and Mrs. } \\
\text { D. talks at her. Mrs. D. does not directly address any } \\
\text { of the student's questions. }\end{array}$ \\
\hline 2 & $\begin{array}{l}\text { Same as Visit 1, but the student says she feels "restless } \\
\text { and frustrated." }\end{array}$ \\
\hline 3 & $\begin{array}{l}\text { The student gives Mrs. D. "cute little raisin rolls." Mrs. } \\
\text { D. is touched by the gesture and indicates she wants } \\
\text { to "do more for herself." The student offers the activ- } \\
\text { ity choices of making muffins from a mix, making a } \\
\text { cat toy, or taking a walk. Mrs. D. selects taking a walk. } \\
\text { Mrs. D. talks "with, rather than at" the student, who } \\
\text { in turn labels the visit "amazing." }\end{array}$ \\
\hline 4 & $\begin{array}{l}\text { Mrs. D. has dinner ready for the student. Mrs. D and the } \\
\text { student take a walk, and Mrs. D. talks about the travel- } \\
\text { ing she and her husband enjoyed. After the walk, the } \\
\text { student asks Mrs. D. to play the organ. A playful ex- } \\
\text { change results. }\end{array}$ \\
\hline 5 & $\begin{array}{l}\text { The student cannot reach Mrs. D. The cat died and the } \\
\text { student is concerned about how Mrs. D. will adjust to } \\
\text { this loss. Mrs. D. is found playing with new cat, Sa- } \\
\text { mantha. Mrs. D. and the student share role confusion. } \\
\text { The student hangs drapes, winds the clock, and } \\
\text { views Mrs. D.'s jewelry. }\end{array}$ \\
\hline 6 & $\begin{array}{l}\text { Mrs. D. makes dinner for the student and saves her the } \\
\text { last piece of raisin bread. The student brought a } \\
\text { muffin mix and Mrs. D. makes the muffins with no } \\
\text { difficulty. They play the organ again, and the student } \\
\text { learns that Mrs. D. had asked the social worker for } \\
\text { transportation to the grocery store. The student } \\
\text { thinks about Mrs. D.'s use of a "sick role." }\end{array}$ \\
\hline 7 & $\begin{array}{l}\text { Mrs. D. cooperates so that the student can complete a } \\
\text { questionnaire on the client's health status. Mrs. D } \\
\text { reports an attempt to walk to her hairdresser's. }\end{array}$ \\
\hline 8 & $\begin{array}{l}\text { The student's planned outing is undertaken. This } 3 \text {-hr } \\
\text { visit includes a bus ride with a change to another } \\
\text { line, stops in four stores, a quick visit to say hello to } \\
\text { Mrs. D.'s hairdresser, and a sidewalk discussion with } \\
\text { Mrs. D.'s neighbor, a physician. }\end{array}$ \\
\hline 9 & $\begin{array}{l}\text { Mrs. D. reports exhaustion from the previous day's ac- } \\
\text { tivities, which involved making vegetable soup and } \\
\text { cleaning. The student urges energy conservation. } \\
\text { The student promises to call Mrs. D. after the holi- } \\
\text { days and says good-bye. }\end{array}$ \\
\hline
\end{tabular}

Note. Quotations are those of the student (Ms. R.).

${ }^{2}$ Based on the scudent's (Ms. R.'s) field notes.

Ms. R. visited Mrs. D. nine times over the 4 months of her senior year. The visits averaged $2 \mathrm{hr}$ each and totaled $18.5 \mathrm{hr}$, not including travel and telephone communication with the physician and social worker. Ms. R. also met with her faculty and laboratory advisers for an additional $3 \mathrm{hr}$.

\section{Analysis}

The following student-based themes emerged from Ms. R.'s field notes concerning Mrs. D.: (a) difficulty with initiating activities, (b) control issues, (c) trust issues, and (d) setting limits and feeling comfortable with them. These four themes were typical of those expressed by other students.

Activity initiation. Faculty advisers noted that students repeatedly struggled with activity initiation.
This struggle was reflected in four ways: (a) difficulty with thinking of appropriate choices, (b) failure to direct the client and take responsibility for activity during the visit, (c) failure to build on the client's suggestions, and (d) poor grading of the activity. A typical example is the student who makes one activity suggestion that the client rejects outright or accepts reluctantly. The student feels like a failure and becomes immobilized; he or she is fearful of risking further rejection, yet must find a way to proceed.

Once students were guided and prodded by faculty advisers, they discovered that clients' reluctance or rejection may stem from a fear of trying something new and risking failure. The students were advised to prepare for their visits by offering three activity choices of parallel grading to involve clients in the decision-making process. Students reported feeling nervous because of the lack of direct supervision. In fact, they even had to evaluate their own performance, professional behavior, and adaptation decisions.

Control. Another recurring theme is that of control, that is, who is directing the content or topic of the interaction. Mrs. D. and the student grappled with this issue throughout their interaction. During the last visit, Mrs. D. asked Ms. R. to go grocery shopping for her, although she had a grocer who delivered her orders. The student had apparently worked out an uneasy give-and-take situation, in which she offered activities for Mrs. D. but also performed household chores. Mrs. D. verbally dominated initial interactions by describing peripheral issues, requesting chore services, and hiding information. Ms. R. wisely respected Mrs. D.'s need for control and used it productively, because she wanted to prepare Mrs. D. for success after she completed the program. Students have to develop a balanced view in which control is shared advantageously by both parties.

Trust. The third issue was trust. Initially, Mrs. D. asked the student to sit by the door. Only after a successful activity-sharing tea and muffins purchased by the student and taking a walk outside-was Mrs. D. able to invite Ms. R. into her kitchen. The client also showed trust by preparing meals for the student, teasing, and sharing treasured photographs and jewelry. As trust increased, Mrs. D. began to act on Ms. R.'s ideas, but still maintained control by not telling Ms. R. that her ideas were useful. Students long for this type of affirmation, forgetting that they need to look for support from sources other than their clients. Mrs. D. also became more independent in housekeeping, shopping, and getting out of her house.

Limits. The final issue was one of limits. Both the client and the student had to recognize the limits of the intervention. Because only the environment was adapted, treatment was indirect. The student can only offer interventions that involve minimal construction, 
cost, and time. One client wanted a student to build a ramp for the outside of her home. The student began to plan for this until faculty guided her to other resources. Thus, students learn that their job is to promote maximum independence in their client but that doing everything for the client will not lead to enduring change.

It is important to note that the student used crafts or activities of daily living to gain the client's trust and then gradually incorporated more of the environment into the activity experience, thereby increasing the client's feelings of mastery and competence. Initial choices reflected some superficial connection to Mrs. D.'s interests, but as the student learned more about Mrs. D she could choose activities connected to more potent interests. Choices such as walking, cleaning, preparing a meal, shopping, and socializing with significant others offered evidence of Mrs. D.'s increased energy and recommitment to a daily routine.

\section{Discussion}

The use of participant observation as a method to gain insight into a client's life-style refocuses the student therapist on the environment rather than on the client's pathology or deficits. This orientation encourages students to suspend a medical treatment model and gain sensitivity to clients' values and interests and how these influence all aspects of the treatment process (Rogers, 1982a). A service provision model based on collaboration between the therapist and the client creates a mutually satisfying process in which culturally appropriate adaptations reflecting the client's values are introduced to improve daily functioning in persons with chronic disabilities. Initially, students are uneasy about visiting clients in their homes. Listening and working in collaboration with clients can be difficult, because students are anxious to apply direct treatment techniques. Nevertheless, by the end of 10 weeks, students demonstrate awareness of the clients' life-styles and interests and can identify conflicts between their own values and those of their clients.

This training approach also provides a unique service to clients who tencl to be underserved or inadequately addressed by the health care system. Student case reports demonstrate that although clients were previously served by a number of health professionals, basic concerns for daily living are often ignored. Major gaps in treatment planning and provision of care exist because the health care team does not understand the client's interests and values and does not collaborate with the client in problem solving. The use of a collaborative approach involving environmental assessment and life-style considerations leads to the introduction of environmental ad. aptations that match the client's life-style. Although the adaptations need not be elaborate, the selection, implementation, and use of such devices must reflect the client's and caregiver's participation in the problem-solving process. The client's interests can be expanded from participation in an activity to a task that has personal or socially derived importance to the client and caregivers.

\section{Summary}

This paper described a training method for occupational therapy students that can be adapted to targeted client populations, such as caregivers of elderly persons with physical disabilities or dementia and persons with psychiatric disorders. The training introduces students to unstructured interview and observational methodologies, provides a unique clinical experience in clients' homes, focuses on environmental forces shaping competency and client func. tioning, and provides a needed service to those persons who are underserved.

\section{References}

Allen, C. (1985). Occupational therapy for psychiatric diseases: Measurement and management of cognitive disability. Boston: Little, Brown.

Barris, R. (1982). Environmental interactions: An ex. tension of the Model of Human Occupation. American Journal of Occupational Therapy, 36, 637-644.

Barris, R., Kielhofner, G., Levine, R., \& Neville, A. M. (1985). Occupation as interaction with the environment. In G. Kielhofner (Ed.), A Model of Human Occupation: Theory and application (pp. 42-62). Baltimore: Williams \& Wilkins.

Burke, I. P. (1977). A clinical perspective on motivation: Pawn versus origin. American Joumal of Occupational Therapy, 31, 254-258.

Cubie, S. H. (1985). Occupational analysis. In G. Kielhofner (Ed.), A Model of Human Occupation: Theory and application (pp. 147-155). Baltimore: Williams \& Wilkins.

Cynkin, S. (1979). Occupational therapy: Toward bealth through activities. Boston: Little, Brown.

Dunning, H. (1972). Environmental occupational therapy. American Journal of Occupational Therapy, 26, 292-298.

Dunton, W. R. (1918). The principles of occupational therapy. Public Health Nursing, 10, 316-321.

Dunton, W. R. (1928). Prescribing occupational ther. apy for nurses. Springfield, IL: Charles C Thomas.

Elliott, M. S., \& Barris, R. (1987). Occupational role performance and life satisfaction in elderly persons. Occu. pational Therapy Journal of Research, 7, 215-224.

Hall, E. T. (1969). The bidden dimension. Garden City, NY: Anchor.

Hall, E. T. (1977). Beyond culture. Garden City, NY: Anchor.

Institute of Medicine and National Research Council. (1988). America's aging: The social and built environment in an older society. Washington, DC: National Academy Press. 
Kannegieter, R. B. (1980). Environmental interactions in psychiatric occupational therapy-Some inferences. American Journal of Occupational Therapy, 34, 715-720.

Kielhofner, G. (1985). The human being as an open system. In G. Kielhofner (Ed.), A Model of Human Occupation (pp. 2-11). Baltimore: Williams \& Wilkins.

Kielhofner, G., \& Burke, J. P. (1980). A Model of Human Occupation, part 1. Conceptual framework and content. American Journal of Occupational Therapy, 34, $572-581$

Kielhofner, G., \& Burke, J. P. (1985). Components and determinants of human occupation. In G. Kielhofner (Ed.), A Model of Human Occupation (pp. 12-36). Baltimore: Williams \& Wilkins.

Kielhofner, G., Burke, J, P., \& Igi, C. H. (1980). A Model of Human Occupation, part 4. Assessment and intervention. American Journal of Occupational Therapy, 34, 777-788.

Langness, L. L., \& Frank, G. (1986). Lives: An anthropological approach to biography. Novato, CA: Chandler \& Sharp

Lawton, M. P. (1983). Environment and other determinants of well being in older people. Gerontologist, 23 , 349-357.

Lawton, M. P., \& Nahemow, L. (1973). Ecology and the aging process. In C. Eisdorfer \& M. P. Lawton (Eds.), The psychology of adult development and aging (pp. 619-673). Washington, DC: American Psychological Association.

Levine, R. E., \& Brayley, C. R. (in press). A contextual approach to performance intervention. In $\mathrm{C}$. Baum \& C. Christiansen (Eds.), Contemporary occupational therapy practice. Thorofare, NJ: Slack.

Maguire, G. H. (Ed.). (1987). Environmental issues for the health professions [Special issue]. Topics in Geriatric Rebabilitation, 3(1).

Mosey, A. C. (1968). Occupational therapy: Theory and practice. Medford, MA: Pothier Brothers
Mosey, A. C. (1973). Activities therapy. New York: Raven Press.

Murray, H. (1938). Explorations in personality. New York: Oxford.

Parent, L. H. (1978). Effects of a low-stimulus environment on behavior. American Journal of Occupational Therapy, 32, 19-25

Pedretti, L. W. (1981). Occupational therapy: Practice skills for physical dysfunction. St. Louis: Mosby.

Philadelphia Corporation for Aging. (1989). Older Philadelphians: Needs, services $\&$ future directions. Philadelphia: Author.

Reilly, M. (1974). An explanation of play. In M. Reilly (Ed.), Play as exploratory learning: Studies of curiosity behavior (pp. 117-149). Beverly Hills, CA: Sage.

Rogers, J. C. (1982a). Order and disorder in medicine and occupational therapy. American Journal of Occupational Therapy, 36, 29-35.

Rogers, J. C. (1982b). The spirit of independence: The evolution of a philosophy. American Journal of Occupational Therapy, 36, 709-715

Rogers, J. C. (1983). Eleanor Clarke Slagle Lectureship-1983; Clinical reasoning: The ethics, science, and art. American Journal of Occupational Therapy, 37, 601-616.

Schon, D. A. (1983). The reflective practitioner: How professionals think in action. New York: Basic.

Spradley, J. P., \& McCurdy, D. W. (1980). Conformity and conflict. Boston: Little, Brown.

Tracey, S. E. (1912). Studies in invalid occupation: A manual for nurses and attendants. Boston: Whitcomb \& Burrows

U.S. Department of Health and Human Services. (1982). Coverage of services: Occupational therapy. In Medicare bome bealth agency manual, $\$ 205.2$, p. 15.1 (HCFA Publication No. 11). Washington, DC: U.S. Government Printing Office. 